\title{
APROXIMAÇÕES ENTRE O PENSAMENTO DE PAULO FREIRE E RODOLFO KUSCH
}

\author{
Cláudio Roberto Brocanelli
}

Universidade Estadual Paulista - UNESP, Departamento de Administração e Supervisão Escolar, Marília, SP. E-mail: claudiobrocanelli@gmail.com

\section{RESUMO}

Este artigo dá continuidade ao desenvolvimento de Projeto de Pesquisa Docente, em estudos sobre Paulo Freire e sua atuação com a educação como uma prática da liberdade da pessoa a fim de que ela tenha um desenvolvimento crescente de libertação de seus medos e entraves da sociedade excludente; Freire quer dar condições de conhecimento e de vida que sejam mais dignos e de acordo com uma realidade que seja mais justa e em que todas as pessoas possam participar dos bens culturais de sua sociedade. Além da busca de uma libertação, é fundamental que se supere o medo dessa liberdade; com a educação, não no modelo já planejado, definido e caracterizado pelo dominador, mas considerando a sua realidade, suas misérias e sua atitude de resignação, na busca de contribuições e com a finalidade de ver-se na sua realidade sofrida e construir um 'quefazer' novo, que o integre e dê forças intelectuais, morais, políticas e sociais para a superação daquela resignação. Da mesma forma, pensando uma postura e uma filosofia sul americana, Rodolfo Kusch desenvolveu um pensamento que prima pelo reconhecimento de si e do valor que há nesta sociedade latino americana. Comumente, nossa educação e nossa formação têm sido construídas a partir de modelos externos e estrangeiros em que o povo se desfez de uma cultura deste chão para cumprir deveres determinados por outros; há, constantemente, a sobreposição de culturas estrangeiras esmagando a cultura local. Assim, há um chamamento para que novamente o povo sul americano olhe para si e veja sua importância, seu valor, sua cultura, de forma que a partir daí, do que há já construído, retome sua dignidade e se abra a um 'quefazer' a partir do que é e daquilo que já construiu. Desse modo, olhando para os dois autores, seu pensamento e por meio de pesquisa teórica e bibliográfica, nosso objetivo é verificar os conceitos que se aproximam e dar contribuições ao pensamento filosófico latino americano no que se refere à educação como processo formativo que se dá a partir do que é a própria realidade.

Palavras-chave: Educação; Consciência; Liberdade; Freire e Kusch.

\section{APPROXIMATIONS BETWEEN THE THOUGHT OF PAULO FREIRE AND RODOLFO KUSCH}

\begin{abstract}
This article continues the development of a Project of Teaching Research in studies about Paulo Freire and his work with education as a practice of the freedom of the person so that it has an increasing development of liberation of its fears and obstacles of the excluding society; Freire wants to give conditions of knowledge and life that are more dignified and according to a reality that is more just and in which all people can participate in the cultural assets of their society. Besides the search for a liberation, it is fundamental that the fear of this freedom be overcome; with education, not in the model already planned, defined and characterized by the domineering, but considering its reality, its miseries and its attitude of resignation, in the search of contributions and with the purpose of seeing
\end{abstract}


itself in its suffered reality and constructing a ' to make it new, to integrate it and give intellectual, moral, political and social forces to overcome that resignation. Likewise, thinking of a South American philosophy and posture, Rodolfo Kusch developed a thought that emphasizes the recognition of himself and the value that exists in this Latin American society. Commonly, our education and formation have been built on foreign and foreign models in which the people have discarded a culture of this ground to fulfill duties determined by others; there is constantly the overlap of foreign cultures crushing the local culture. So there is a call for the South American people to look at themselves again and see their importance, their value, their culture, so that from there, from what has already been built, they take up their dignity and open themselves to a 'to do' from what is and what has already built. Thus, looking at the two authors, their thinking and through theoretical and bibliographical research, our objective is to verify the concepts that are approaching and to give contributions to Latin American philosophical thought in what concerns to education as a formative process that is given to from reality itself.

Keywords: Education; Consciousness; Freedom; Freire and Kusch.

\section{INTRODUÇÃO}

A educação brasileira ganhou contribuições importantes de Paulo Freire em épocas em que o projeto educativo se iniciava de forma mais consistente e com a atuação do Estado. Assim, a perspectiva de uma educação para todas as pessoas começava a ser vislumbrada por muita gente. Durante muito tempo ainda, aquilo que estava reservado a pessoas mais abastadas ou que tinham algum interesse em seguir carreira religiosa, continuava sendo privilégio. Aos poucos, passa a ser possibilidade, chegando aos nossos dias como escola obrigatória, para todos e com as características próprias como gratuita, laica, pública e de qualidade, apesar de sérios problemas e desafios ainda serem obstáculos que nos chamam à sua superação.

É mister que se tome como pauta de discussão e luta permanente a busca por uma educação que leve as pessoas à dignidade de vida. Paulo Freire sempre buscou desenvolver uma metodologia de trabalho e estudos que primasse pela conquista de novas possibilidades de vida que não meramente aquela determinada por um poder soberano e dominador. Seu desejo sempre foi o de que as pessoas, por meio da educação, possam, ao mesmo tempo em que são alfabetizadas, alcançar a consciência de si e a respeito da sociedade em que vivem, superando os limites, fazendo parte da sociedade e, em grande medida, possam escolher outra forma de vida que não a de resignação.

Freire, além de suas contribuições no campo da educação brasileira, deixou legado a toda educação latino americana. Seu pensamento é recurso para se pensar a vida marginalizada que é aparente e escancarada na América Latina; vida tomada, vida de sofrimento, vida abandonada, cultura invadida, vida resignada e explorada. Tudo isso, de algum modo precisa ser superado pelas próprias mãos humanas, quiçá, de acordo com as crenças aqui ainda persistentes, pelas divinas, as quais dão brilho aos olhos de povos pobres sofredores. A libertação não pode ser algo dado, mas iniciado no terreno dos próprios povos sul-americanos.

Com isso, desejo aqui considerar uma possibilidade: pensar com Paulo Freire e Rodolfo Kusch, juntando pensamentos, ideias e conceitos importantes à nossa educação e caros aos dois autores. Kusch fez estudos com povos indígenas e demais povos sofridos da América Latina. Considerou que há uma forte invasão de pensamentos e culturas que dificultam a vivência daquilo que é cultura integrante do ser daqui, destas terras. A invasão norte americana e europeia são elementos que impedem a vida genuína do povo destas terras; culturalmente, nós fomos tomados e continuamos a 
ser tomados e orientados por pensamentos, culturas e formas de vida não nossas. Kusch destaca o valor de pensar uma filosofia a partir do que há aqui. A partir do ser legitimamente aqui constituído, com sua cultura, suas crenças, seus valores, seus afazeres e tudo o que pode ser considerado deste território.

Há, reinando neste território, um medo de ser nós mesmos e o medo de pensar 'o nosso' como forma de filosofar a partir que é e há aqui, como processo de posicionamento e libertação. Toda nossa educação, nossa escola, valoriza o setor culto, aquilo que já foi legitimado pelo poder dominador e que deve ser transmitido, ensinado, decorado e assimilado por todos. Por sua vez, há um setor popular desprezado; aquilo que realmente é e existe aqui, deixado de lado para que aquele primeiro setor se sobressaia. É comumente frisada a técnica acadêmica a fim de que não haja o inesperado; tudo pode ser definido, determinado e programado num planejamento certeiro, desprezando a surpresa, que poderia ser a contribuição do outro, do ser daqui e daquilo que é ou seria a cultura inicial.

Assim, como primeiro processo de pensamento, é fundamental que se considere, com os dois pensadores, a cultura do medo e a falta de uma educação como fonte de libertação. É oportuno criar espaços para pensar filosoficamente a partir daqui mesmo, do que constitui nosso ser latino americano. A cultura indígena ou do povo aborígine, ainda que já misturado, é o primeiro recurso para, antes de qualquer libertação, se viva como se é. Sugere-se viver a partir de si mesmo, antes de assimilação cega de culturas estrangeiras como sendo a verdade absoluta. Superação de vida submissa, resignada e subserviente é fundamental para reconhecer os valores do que já se tem, que é cultura própria.

Desejo pensar, pese o trabalho gigante dos autores, a realidade da escola, da educação, do processo educativo que se dá, comumente, em forma de imposição, desconsiderando tudo o que culturalmente cada aluno leva para a escola. Nossa postura, como professores, mais se repete como dominadores do que como prática de uma libertação e de uma leitura da palavra como possibilidade de compreensão do mundo e de sua releitura. Desejo criar meios para compreender e possibilitar compreensões nesse sentido, em sala de aula e em qualquer outro ambiente que promova educação como processo de formação humana.

Nossos objetivos e problematização para pensar tais questões neste processo de estudos, de pesquisa e de compreensão da realidade latino americana buscam a aproximação dos pensamentos dos dois autores, justamente por serem pensadores latino-americanos, como fomento para uma reflexão sobre o aqui e o que é daqui, de nossa cultura legitimamente. O objetivo centra-se nos estudos sobre o pensamento de Paulo Freire e de Rodolfo Kusch porque ambos elaboram crítica à sociedade instalada na América Latina, priorizando o pensamento culto, definido e legitimado, sobrepondo-se àquilo que é culturalmente nascido nestas terras.

\section{METODOLOGIA}

Com a consciência acerca destas reflexões, meu desejo é construir paulatinamente um pensamento que valorize o outro não reconhecido e que dê razões para novas reflexões e possibilidades, na educação e nos diversos lugares em que tais reflexões chegarem. É sempre oportuno um pensamento que instigue novas ações e novos comportamentos como postura ética na sociedade em que estamos todos inseridos.

Quero aqui aproximar o pensamento de Freire e Kusch de maneira que suas reflexões dêem força para novas ações educativas. Ambos são de um mesmo ambiente, o sul americano; este merece tais reflexões e resgate de pensamentos anteriores a fim de que novas possibilidades educativas surjam e resgatem o homem sofrido de suas misérias e fortaleça uma Filosofia desde este seu lugar. 
Pensar com os autores citados é condição para a superação de limites construídos e que o constituíram como homem resignado.

Desde as primeiras ações, este estudo percorrerá o estudo teórico e bibliográfico, aproximado os pensamentos dos dois autores: Freire e Kusch. Durante este estudo, a fim de conhecimento mais profundo acerca de Rodolfo Kusch, será realizadar visita à Universidade Três de Fevereiro - UNTREV na Argentina, a fim de conhecer melhor as pesquisas elaboradas por Carlos Cullen, pesquisador das obras de Kusch, por meio de entrevista semi estruturada, o que dará novos elementos para complementar os estudos e elaborar os textos pretendidos. De forma a aproximar os pensamentos, isso se dará por meio da pesquisa, tomando elementos e conceitos de seus pensamentos, em especial, quando tais pensadores tratam da resignação, do medo, da liberdade, da exploração e das possibilidades de superação dos limites constituídos na cultura sul-americana.

Após aprofundar os estudos e a aproximação dos pensamentos de Freire e Kusch, por meio dos conceitos e reflexões, será feita a avaliação dos conceitos aproximados de forma a oferecer subsídios filosóficos para novas reflexões, ao leitor ou qualquer outro interlocutor, para se chegar a novas possibilidades de reflexão, especialmente em ambientes escolares, sejam básicos ou superiores.

Para que tais estudos obtenham fundamentações às ideias comentadas acima, serão utilizadas obras de Freire, especialmente: Pedagogia do Oprimido, Educação como Prática da Liberdade, Pedagogia da Autonomia, Extensão ou Comunicação, Medo e Ousadia, dentre outros que possamos considerar complementares durante os estudos; e de Kusch: Obras Completas Tomo I e Tomo II, além de buscar outros estudos a respeito de seu pensamento, como os de Carlos Cullen, com quem manteremos contato na Argentina.

\section{RESULTADOS}

Este estudo demonstra sua importância na medida em que aproxima o pensamento de dois autores do século XX, desvelando os valores do povo latino americano e seu pensamento; aquilo que é da raiz de um povo, aquilo que surge de seus desafios, dificuldades e miséria, aquilo que retrata sua natureza, pessoal e ambiental, tudo isso deve ser elemento valoroso de sua contribuição para o pensamento e a reflexão, também filosófica, com finalidades de um crescimento que seja mais coerente e integrado com a realidade onde estão imersos, inseridos e vivenciando. Por esse caminho, tanto Freire quanto Kusch buscam tais elementos como constitutivos de um povo que, em grande medida, foi explorado e permaneceu inerte; o que veio e continua vindo de fora, além da imposição, é aceito por haver acostumado a um ritmo de vida passiva. Portanto, urge repensar sua posição; urge oferecer os elementos próprios daqui, deste lugar, para que sejam pensadas novas maneiras. Como nos lembram alguns filósofos, é preciso pensar de outro modo. É isso que os autores em questão nos propõem: pensar de outro modo, pensar de outro lugar (do aqui) e fazer valer o que aqui é vivido.

Freire (1961), persiste na criação de uma Pedagogia do Oprimido. As atitudes daquele que é oprimido não são vistas e nem consideradas. Seja qual for a modalidade ou o ambiente, todo oprimido não é visto porque é colocado em condição de passividade. Porém, há saídas, ainda que difíceis de acontecerem: pode haver uma libertação do medo por parte do que é oprimido ou uma nova postura, ajudando a libertar, o que implica na ajuda da parte de quem oprime, o que é uma situação mais difícil. De todo modo, o oprimido pode inserir-se numa forma de educação como prática da liberdade (1967). Nessa práxis, as relações vão sendo modificadas e vai ocorrendo a libertação na forma de tomada de consciência de seu lugar no mundo. Se a leitura do mundo já existe, por meio da leitura da palavra, em sua Carta de Paulo Freire aos Professores (2001) haverá nova leitura do mundo, nova forma de ver as condições de vida e busca de consciência libertadora 
com o 'quefazer' novo, libertando-se e hominizando-se como parte integrante do mesmo mundo em que todos estão inseridos, sem classificações estereotipadas pelo estranho, pelo de fora, mas na criação de nova forma de vida conjunta a partir de dentro mesmo.

Assim, justifica-se um estudo que dê condições de pensar e educar para a libertação; isso implica na libertação permanente e constante de todos, sem exceção. Quando Kusch propõe pensar a singularidade do homem latino americano, sua intenção é desvelar as condições de vida submetida e resignada aos estranhos, ou estrangeiros; seu pensamento se aplica à compreensão da realidade. Numa postura antropológica e filosófica, tende a problematizar a construção do pensamento do povo daqui. Kusch (1976) quer pensar e propor pensar sobre o 'ser da América' que comumente vive épocas de crise; essa época, infelizmente, é uma constante da qual precisamos nos livrar na forma de consciência do que se é e do que se passa aqui.

Sua reflexão parte de uma geocultura do homem americano, o qual vive um modo de ser na crise permanente, pois desprezado, diminuído, tornado resignado aos meios dominantes externos, estrangeiros e exteriores a si mesmo. Assim comportando-se, age com medo 'de nós mesmos' e com o medo de pensar uma filosofia que seja daqui, que seja nossa. Há, já caracterizado entre o povo sul americano, a dicotomização entre setor culto - o como deve ser e fazer as coisas - e o setor popular o que se é, porém, desvalido.

Assim, Kusch (1976) defende a Filosofia como algo que se constitui, e é aquilo que deve ser iniciado e instigado aqui em nosso lugar; o pensamento popular é algo que se constitui antes de ser apresentada a técnica, antes do outro cristalizado. Então, seria interessante pensar primeiramente a ética, para depois explicar o como e porque fazer do modo como é apresentado. Aqui poderíamos apresentar o valor da surpresa, o que também tem sido ignorado pelo homem do exterior. Este se vale da técnica para não encontrar-se com o inesperado, pois isso está implicado em sentir medo. Por outro lado, com a técnica, com a certeza, não se experiencia o medo, a surpresa. Portanto, uma prática de vida que vive a certeza promove a esterilidade filosófica.

\section{DISCUSSÃO}

Analogamente, em nosso meio acadêmico e no sistema educacional, dificilmente se considera a vida de nossos alunos, a vida de nosso povo. Parte-se do já sabido, daquilo que a escola tomou para si como verdade e tudo o que o poder dominador permite ser estudado. Pouquíssimas ações primam por valorizar o que é das bases, do povo, de uma cultura local, etc. O que mais vale é o que está didaticamente e estrategicamente determinado para os estudos, desde a primeira escola até a universidade. Portanto, localizar tal realidade consiste em declarar que há a necessidade de superação das violências já cometidas e das possibilidades de novas formas de vida. A importância da problematização das invasões culturais, do desfavorecimento e desvalorização do que é daqui são situações fundamentais para a conscientização e as novas leituras de mundo, considerando as culturas locais. Por meio de uma Filosofia da América Latina e seu reconhecimento, este artigo objetiva dar condições para o pensamento dessas questões na educação, em sala de aula e em ambientes que propiciem um crescimento intelectual, moral, social e político de nosso povo e de nossa realidade.

Na educação, especialmente a escolar, se tem formulado questões e ideias como prevenção; então, se educa para prevenir e prever, como sendo um marxista do mesmo. Há uma busca da resistência, porém, esta como certezas do que já fazer pronto, acabado; isso se dá por meio de reflexão que dá resposta pronta, não como atirar-se e atrever-se a pensar o que há e o que é daqui. Nessa perspectiva, torna-se necessário repensar as dicotomias cristalizadas: a técnica ou a surpresa; a elite ou o povo. São dimensões diferentes e que tornam-se determinadas e deterministas desde o 
dominador, desconsiderando o lugar e o ser dominado. O exemplo oferecido por Kusch (1976) em seu texto é que 'se extrai o mesmo mineral porque, senão, se perde tempo e dinheiro'. Então, com a coragem do ainda não, seria necessário provocar, cavar e buscar além do já visto, ou seja, filosofar a partir do não visto, do escondido, do que está nas entrelinhas ou em possíveis reflexões ainda não desveladas.

Há, no homem sul americano, o medo de ser inferior, pois já foi catalogada como inferior a América do sul, seja nos mapas, seja no ser humano, seja em sua cultura. Isso cria no ser daqui o panorama de um 'superior como o útil e o inferior como o inútil', assimilando uma postura resignada. Se em verdade cristalizou-se uma aculturação desde fora, precisamos fazer a viagem que nos leve até as raízes de nossa existência, por dentro.

Superar o medo da história pode ser o primeiro passo para a libertação; há aqui uma história acidentada, não linear, com grandes diferenças entre campo e cidade, centro e periferia, o que já define rico e pobre. Os analfabetos, no segundo grupo citado, não fazem parte da história. Foi construída a história a partir de fatos e coisas, desprezando o homem; não a história do homem daqui. A história divulgada trouxe personagens criadas como superiores, desfazendo-se de pessoas que aqui se constituíram até algum certo momento. Essas pessoas morreram, ou melhor, foram aniquiladas; precisam ser resgatadas de seu poço interior.

A fim de concluir este texto, damos a devida atenção para a construção do conhecimento acerca da aproximação dos autores pesquisados e uma atenção especial ao conhecimento das obras de Rodolfo Kusch, uma vez que o pensamento de Paulo Freire já é de meu conhecimento e já há percorrido uma trajetória de reflexão sobre seus conceitos ocorridos em eventos, em aulas e textos já escritos. Com tais iniciativas, nossos estudos dos pensamentos de Paulo Freire e Rodolfo Kusch e suas aproximações darão suporte para continuar uma reflexão sobre a educação na América Latina e a formação de um povo, seus limites e possibilidades, bem como buscar uma Filosofia da Educação que privilegie a vida do outro, do sofrido e miserável, do dominado, do sem voz, em sala de aula ou fora dela, que pode nos dar o que pensar, mas que, comumente, é desprezado, colocado à parte e tornado resignado, não por sua vontade, mas por forças estranhas, externas e estrangeiras, as quais são motivadas pela postura dos seus professores, mantendo o poder e o domínio sobre o outro, impedindo sua ação, sua expressão, sua participação e sua contribuição aos momentos em que a sala de aula poderia se tornar um ambiente rico para o pensamento e formulações a partir do que aí é inscrito por todos os presentes.

\section{REFERÊNCIAS}

FREIRE, P. Pedagogia do Oprimido. Paz e Terra. Rio de Janeiro, 1961.

. Educação como Prática da Liberdade. Paz e Terra. Rio de Janeiro, 1967.

CAMBEIRO, F. G. Rodolfo Kusch - Geocultura Del Hombre Americano. Colección Estúdios Latinoamericanos. Buenos Aires, 1976.

KUSCH, R. Obras completas. Tomo I e Tomo II. Editorial Fundación Ross. Argentina. 1998. 